\title{
Carpal tunnel syndrome and provocative clinical tests
}

Beuy Joob ${ }^{1 *}$ and Viroj Wiwanitkit ${ }^{2}$

\begin{abstract}
This is a letter to the editor commenting on "Carpal tunnel syndrome: evaluation of its provocative clinical tests."
\end{abstract}

Keywords: Carpal tunnel, Syndrome, Provocative

\section{Introduction}

This is letter to editor commenting on "Carpal tunnel syndrome: evaluation of its provocative clinical tests."

\section{Main text}

Dear Editor, we read the publication on "Carpal tunnel syndrome: evaluation of its provocative clinical tests" with great interest [1]. Arab et al. evaluated provocative clinical test for carpal tunnel syndrome and concluded that "Arm raising test (ART) is a simple, reliable, and easily performed test for evaluating carpal tunnel syndrome; it is superior to other tests and could be used also to assess improvement after surgery [1]." We agree that the ART should be a good test and appropriate for any setting with limited resource. However, the diagnostic property might vary and depends on the clinical skill of the practitioner. Also, different provocative tests have different diagnostic properties. Tetro et al. mentioned that wrist flexion and median-nerve compression test was superior to other provocative tests including Tinel's percussion test, Phalen's wrist flexion test, and the carpal compression test in terms of diagnostic properties [2]. The observed specificity of wrist flexion and median-nerve compression test is $99 \%$ [2] comparing to 97.1\% of ART [1].

\section{Conclusions}

This is a letter to the editor commenting on "Carpal tunnel syndrome: evaluation of its provocative clinical tests."

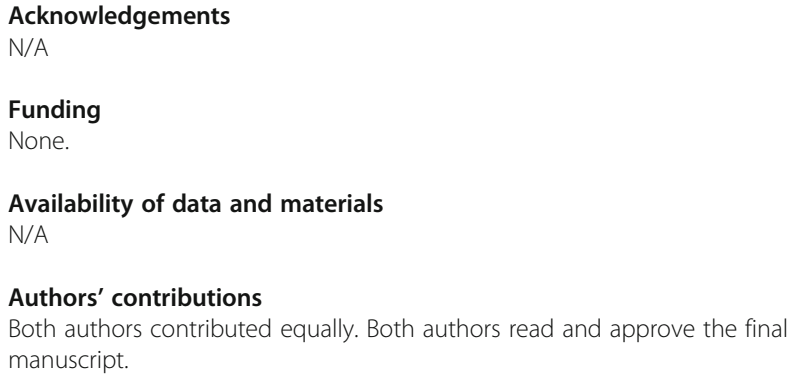

Consent for publication

Not Applicable.

Competing interests

The authors declare that they have no competing interests.

\section{Publisher's Note}

Springer Nature remains neutral with regard to jurisdictional claims in published maps and institutional affiliations.

\section{Author details \\ ${ }^{1}$ Sanitation 1 Medical Academic Center, Bangkok, Thailand. ${ }^{2}$ DY Patil University, Pune, India.}

Received: 27 December 2018 Accepted: 18 March 2019

Published online: 25 March 2019

\section{References}

1. Arab AA, Elmaghrabi MM, Eltantawy MH. Carpal tunnel syndrome: evaluation of its provocative clinical tests. Egyptian J Neurosurg. 2019;33:14.

2. Tetro AM, Evanoff BA, Hollstien SB, Gelberman RH. A new provocative test for carpal tunnel syndrome. Assessment of wrist flexion and nerve compression. J Bone Joint Surg Br. 1998;80(3):493-8.

* Correspondence: beuyjoob@hotmail.com

'Sanitation 1 Medical Academic Center, Bangkok, Thailand

Full list of author information is available at the end of the article 